\title{
Infection Control Knowledge of Medical Interns before and after Training Intervention in Tanta University Hospital in Egypt
}

Aya Farag El Sebaey ${ }^{1 *}$, Samir Abd El MageedAtlam, El Sayed Abd El Rahman El Kafas ${ }^{1}$ and Hanaa Abd El Aziz Zayed ${ }^{2}$

${ }^{1}$ Department of Public Health and Community Medicine, Faculty of Medicine, Tanta University, Egypt

${ }^{2}$ Department of Occupational Health and Industrial Medicine, Faculty of Medicine, Tanta University, Egypt

*Corresponding author

\section{A B S T R A C T}

Health care associated infections are reported among the top causes of hospital deaths worldwide. Their prevention is a first priority for patient safety in acute care hospitals. Education and training is recommended as a core component

Keywords

Infection control training; medical interns; knowledge

Article Info

Accepted: 12 May 2021 Available Online: 10 June 2021 for effective infection prevention and control programs. This study aimed to assess the infection control knowledge of medical interns before and after intervention of training course in Tanta University Hospital. The study included 268 medical interns who were getting their practical training at Tanta University Hospitals, Egypt during the study period. Knowledge and practices regarding infection control measures were assessed using a predesigned questionnaire sheet before and after intervention. The data have been analyzed through the application of: descriptive frequency, percentages and the inferential analysis that include: Monte Carlo test. The level of statistical significance was adopted at $\mathrm{P} \leq 0.05$. There was a statistically significant $(\mathrm{p}<$ 0.0001 ) increase in good knowledge as regard all infection control measures after intervention. There was improvement in Knowledge grades of studied participants after training.

\section{Introduction}

Infection control refers to all or any strategies, techniques and activities that aim to prevent or minimize the chance of infectious disease transmission at health care facility.(Lobo et al., 2019) (Ibrahim and Elshafie, 2016). Health care associated infections (HCAIs) are reported among the top 10 causes of hospital deaths worldwide. HCAIs have a major impact on healthcare systems including extended duration of hospital stays, increased 
morbidity associated with antibiotic-resistant organisms, increased risks of mortality, and a higher financial burden(Alhraiwil et al., 2020).

Standard isolation precautions are designed to reduce the risk of acquiring occupational infections from both known and unknown sources in healthcare settings. Awareness of and compliance with these recommendations are crucial for the prevention of infections among HCWs (Binalrimal et al., 2019).

Although the healthcare workers are aware of the risk of transmission of infection, the compliance with standard precautions was inadequate and recommended a need for an improvement in knowledge and practices with clear guidelines and a comprehensive program to educate $\mathrm{HCWs}$ regarding compliance with standard precautions. A great portion of the reported HCAIs in Egypt could be attributed to non- compliance of health care workers to SICPs (Lobo et al., 2019).

Education and training is recommended as a core component for effective infection prevention and control programs by the world health organization (WHO) (Tartari et al., 2019).

Several studies from different countries confirmed that young intern were at the highest risk for needle stick injuries. This could be explained by the lack of experience, skills, and confidence of most newly graduated doctors (Gupta et al., 2008; Park et al., 2008).

Hence, it is essential to train health care providers particularly the juniors on the procedure of IPC. It seems logic to start with medical interns who at risk of accidental exposure to infection or may be a source of transmitting infection during their internship due to lack of their knowledge and the infection control practical training. The main aim of this study to assess the infection control, knowledge of medical interns before and after training in Tanta University Hospitals.

\section{Participants and Methods}

\section{Design and setting}

This quasi-experimental study was carried out at Tanta University Hospitals for 4 months

\section{Study population}

The total number of medical interns was 650 . The sample size calculation calculated 200 subjects Data analysis was done for 268 respondents.

\section{Study tools and data collection}

A self- administrated questionnaire was used to assess participant's knowledge before and after the training course. The questionnaire included questions about personal and professional data (code, gender, residence, grade of graduation, current department, and receiving previous training on infection control). Also, it included questions for assessment of knowledge about infection control measures: general information regarding infection control science, hand hygiene, personal protective equipment, needle stick injury prevention and postexposure prophylaxis, health care waste types and management, transmission-based precautions, and asepsis. Scoring of knowledge, each correct response was scored one (1) point and incorrect answer or I do not know was scored zero (0) point. The total responses of each participant were summated and the total score was ranged from (0-95). Every subject who achieved three quarters or more of the total score $(\geq 75 \%)$ was considered to have good knowledge, those achieved from 
one half to less than three quarters $(50 \%$ $<75 \%$ ) were considered to have fair knowledge and those achieved less than one half $(<50 \%)$ was considered to have poor knowledge.

\section{Content of the course}

The contents of infection control training course were prepared by 5 experts in infection control and occupational health based on Egyptian national guide for infection control. It contained epidemiology of health care associated infections, standard infection control precautions, transmission basedprecautions, aseptic techniques, needle stick injury prevention, and post-exposure prophylaxis.

\section{Conduction of the course}

The course was conducted through lectures, posters, audio visuals (videos), and practical training (case studies, case scenarios, role playing, and drill). The studied participants were divided into 12 groups each group included 22 participants. Each lesson was repeated for each group separately. Each lesson was held in 2 weeks and the whole course was lasted for eight consecutive weeks.

They were told to come back after 2 weeks for posttest which was the same as pretest.

\section{Ethical considerations}

Approval from the Ethical Committee of Tanta Faculty of Medicine was obtained. Formal written consent was taken from each studied participant.

\section{Data management}

Statistical analysis was performed using Statistical Package for Social Sciences for Windows, Comparisons between two groups were carried out using paired Monte Carlo test. For qualitative data, the variables were summarized as frequencies and percentages. The level of statistical significance was adopted at $\mathrm{P} \leq 0.05$.

\section{Results and Discussion}

The total number of studied participants was 268. Most of studied participants were males $(63.1 \%)$ and from urban areas $(59.7 \%)$. Approximately two third $(62.7 \%)$ of studied participants were training in medical departments and about one-third (32.1\%) of them received previous infection control training (Table 1).

A statistically significant effect of training course on total score of knowledge and practices was found among studied medical interns as there was a significant increase in percentage of good knowledge and good practices from $39.9 \%$ to $81 \%$ and from $0 \%$ to $43.8 \%$ respectively. $(\mathrm{p}=0.0001)$ (Table 2$)$.

There is statistically significant effect of training course on knowledge grades of studied participants regarding infection control in all the studied infection control measures as $\mathrm{P}=0.0001$ as illustrated in table (9), as; there is significant increase in percentage of studied participants who recorded good knowledge after intervention of infection control training course in general information regarding infection control and hand hygiene before Vs after from $57.1 \%$ and $81 \%$ Vs $84 \%$ and $92.9 \%$ respectively. As regards needle stick injury prevention and post exposure prophylaxis, health care waste types and management, there is statistically significant decrease of poor knowledge percentage from $40.3 \%$ to $12.7 \%, 14.2 \%$ to $6.7 \%$ respectively. As well in knowledge concerns transmission based precautions and asepsis the studied participants recorded highest significant increase in their knowledge after training course $79.5 \%$ to $91.8 \%, 73.1 \%$ to $91 \%$ respectively. There is a statistically significant effect of training course on total score of 
knowledge as there is significant decrease in percentage of studied participants who had a poor knowledge from $10.1 \%$ to $4.9 \%$ and on the other side, there is significant increase in percentage in good knowledge from $39.9 \%$ to $81 \%$ (Table3).

Table 4 There is statistically significant effect of training course on practice grades of studied participants regarding infection control in all studied items of infection control measures as $\mathrm{P} \leq 0.05$ as illustrated in table (10); as regards hand washing; poor practice recorded highest percentage between studied participants $95.8 \%$ which decreased to $33.3 \%$ after intervention of training course, in opposite alcohol based hand rub $64.6 \%$ of studied participants recorded good practice which increase to $100 \%$ after training. As regards personal protective equipment, about two third of them recorded poor practice $66.7 \%$ with statistically significant decrease to $2.1 \%$ after intervention. Regarding sequence of wearing of PPE (Gown, mask and gloves) recorded poor practice in percentages $16.7 \%$, $77.1 \%$ and $20.8 \%$ which decreased significantly to $6.3 \%, 2.1 \%$ and $2.1 \%$ respectively. The same in the sequence of removal of PPE (Gloves, gown, and mask)recorded poor practice in percentages $14.6 \%, 87.5 \%$ and $83.3 \%$ which decreased significantly to $0 \%, 4.2 \%$ and $0 \%$ respectively. As regard medication preparation there was significantly increase in percentage of studied participants with good practice from $0 \%$ to $60.4 \%$ after intervention. Frequency of studied participants according to needle stick injury prevention practice and waste disposal were $93.8 \%$ and $97.9 \%$ had poor practice which decreased significantly to $4.2 \%$ and $0 \%$ after intervention. Finally there is statistically significant effect of training course on total practice score of studied participants as $83.3 \%$ had poor practice before training course intervention which significantly changes to better after course to $0 \%$ had poor practice.
The present study showed a significant improvement in knowledge about infection control measures post-intervention versus preintervention regarding general information, hand hygiene, personal protective equipment, needle stick injury prevention and postexposure prophylaxis, health care waste types and management, transmission-based precautions, and asepsis.

Low pre-intervention scores of the studied medical interns may be related to the time of the baseline assessment, which occurred at the beginning of participants' clinical rotations. They may not have had enough clinical experience and a lack of exposure to observe and learn in the isolation, infectious diseases, or surgical departments. Therefore, they did not sufficiently recognize the importance of infection control procedures(Xiong et al., 2017). Also, lack of resources, excess workload, and time constraint have been reported as major factors influencing the poor practice of infection control in healthcare facilities (Lobo et al., (2019).

A small interventional study in Hong Kong was conducted, where 15 residents and 10 health care professionals received an educational program about infection control. The intervention consisted of an educational program that lasted for 2 weeks after a baseline test at week 1 .

The effectiveness of the program was evaluated by giving a post-intervention test at week 8 to both the intervention and control groups. The researchers reported a 4-point (out of 20) improvement in post-test scores in the intervention group(Ho et al., 2012). Another study conducted in Taiwan focused solely on hand hygiene. With knowledge tests taken pre-intervention and 1 and 3 months post-intervention, the scores of the 2 post-tests were significantly higher than the pre-test (Huang and $\mathrm{Wu}, 2008$ ). 
Table.1 Distribution of studied participants according to personal and professional characteristics

\begin{tabular}{|c|c|c|}
\hline $\begin{array}{c}\text { Personal and professional } \\
\text { characteristics }\end{array}$ & \multicolumn{2}{|c|}{$\begin{array}{c}\text { Study sample } \\
\text { (N=268) }\end{array}$} \\
\hline & N & $\%$ \\
\hline Female & Gender & 36.9 \\
\hline Male & 99 & 63.1 \\
\hline & 169 & 59.7 \\
\hline Urban & Residence & 40.3 \\
\hline Rural & 160 & 1.1 \\
\hline & Grade of graduation & 17.5 \\
\hline Pass & 3 & 36.9 \\
\hline Good & 47 & 44.4 \\
\hline Very good & 99 & 37.3 \\
\hline Excellent & 119 & 62.7 \\
\hline Surgical & Current department \\
\hline Medical & 100 & 32.1 \\
\hline Yes & 168 & 67.9 \\
\hline No & 86 & \\
\hline & 182 & \\
\hline
\end{tabular}

Table.2 Distribution of studied participants according to total knowledge and practices scores of infection control measures before and after intervention

\begin{tabular}{|c|c|c|c|c|c|}
\hline \multirow{3}{*}{$\begin{array}{l}\text { Total knowledge and practice } \\
\text { scores of Infection control } \\
\text { measures }\end{array}$} & \multicolumn{4}{|c|}{ Studied participants } & \multirow{3}{*}{$\begin{array}{c}\text { MCP } \\
\text { (P value) }\end{array}$} \\
\hline & \multicolumn{2}{|c|}{ Pre-intervention } & \multicolumn{2}{|c|}{ Post- intervention } & \\
\hline & $\mathbf{N}$ & $\%$ & $\mathbf{N}$ & $\%$ & \\
\hline \multicolumn{5}{|l|}{ Total score of knowledge $(\mathrm{N}=268)$} & \multirow{4}{*}{$0.0001 *$} \\
\hline Poor & 27 & 10.1 & 13 & 4.9 & \\
\hline Fair & 134 & 50 & 38 & 14.2 & \\
\hline Good & 107 & 39.9 & 217 & 81 & \\
\hline \multicolumn{5}{|l|}{ Total score of practices $(\mathrm{N}=48)$} & \multirow{4}{*}{$0.0001 *$} \\
\hline Poor & 40 & 83.3 & 0 & 0 & \\
\hline Fair & 8 & 16.7 & 27 & 56.3 & \\
\hline Good & 0 & 0 & 21 & 43.8 & \\
\hline
\end{tabular}

N: number; MCP: Monte Carlo Exact *: statistically significant 
Table.3 Effect of infection control training course on knowledge of the studied medical interns.

\begin{tabular}{|c|c|c|c|c|c|}
\hline & \multicolumn{2}{|c|}{$\begin{array}{l}\text { Pre-intervention } \\
(\mathrm{N}=\mathbf{2 6 8})\end{array}$} & \multicolumn{2}{|c|}{$\begin{array}{l}\text { Post- intervention } \\
\quad(\mathrm{N}=\mathbf{2 6 8})\end{array}$} & \multirow[t]{2}{*}{$\begin{array}{c}\text { Test of significance } \\
\text { (p) }\end{array}$} \\
\hline & No. & $\%$ & No. & $\%$ & \\
\hline \multicolumn{6}{|c|}{ General information regarding infection control measures } \\
\hline Poor & 35 & 13.1 & 12 & 4.5 & \multirow[t]{3}{*}{$0.0001 *$} \\
\hline Fair & 80 & 29.9 & 31 & 11.6 & \\
\hline Good & 153 & 57.1 & 225 & 84 & \\
\hline \multicolumn{5}{|c|}{ Hand hygiene } & \\
\hline Poor & 19 & 7.1 & 7 & 2.6 & \multirow[t]{3}{*}{$0.0001 *$} \\
\hline Fair & 32 & 11.9 & 12 & 4.5 & \\
\hline Good & 217 & 81 & 249 & 92.9 & \\
\hline \multicolumn{6}{|c|}{ Personal protective equipment } \\
\hline Poor & 35 & 13.1 & 15 & 5.6 & \multirow{3}{*}{$0.0001 *$} \\
\hline Fair & 84 & 31.3 & 37 & 13.8 & \\
\hline Good & 149 & 55.6 & 216 & 80.6 & \\
\hline \multicolumn{6}{|c|}{ Needle stick injury prevention and post exposure prophylaxis } \\
\hline Poor & 108 & 40.3 & 34 & 12.7 & \multirow{3}{*}{$0.0001 *$} \\
\hline Fair & 106 & 39.6 & 44 & 16.4 & \\
\hline Good & 54 & 20.1 & 190 & 70.9 & \\
\hline \multicolumn{6}{|c|}{ Health care waste types and management } \\
\hline Poor & 38 & 14.2 & 18 & 6.7 & \multirow{3}{*}{$0.0001 *$} \\
\hline Fair & 121 & 45.1 & 53 & 19.8 & \\
\hline Good & 109 & 40.7 & 197 & 73.5 & \\
\hline \multicolumn{6}{|c|}{ Transmission based precautions } \\
\hline Poor & 23 & 8.6 & 11 & 4.1 & \multirow{3}{*}{$0.0001 *$} \\
\hline Fair & 32 & 11.9 & 11 & 4.1 & \\
\hline Good & 213 & 79.5 & 246 & 91.8 & \\
\hline \multicolumn{6}{|l|}{ Asepsis } \\
\hline Poor & 42 & 15.7 & 16 & 6 & \multirow{3}{*}{$0.0001 *$} \\
\hline Fair & 30 & 11.2 & 8 & 3 & \\
\hline Good & 196 & 73.1 & 244 & 91 & \\
\hline \multicolumn{6}{|c|}{ Total score } \\
\hline Poor & 27 & 10.1 & 13 & 4.9 & \multirow{3}{*}{$0.0001 *$} \\
\hline Fair & 134 & 50 & 38 & 14.2 & \\
\hline Good & 107 & 39.9 & 217 & 81 & \\
\hline
\end{tabular}

\# Test used was MCP: Monte Carlo Exact p value, *: statistically sig as p value $\leq .05$ 
Table.4 Effect of infection control training course on practice of studied medical interns

\begin{tabular}{|c|c|c|c|c|c|}
\hline & \multicolumn{2}{|c|}{$\begin{array}{l}\text { Pre-intervention } \\
(\mathrm{N}=48)\end{array}$} & \multicolumn{2}{|c|}{$\begin{array}{l}\text { Post- intervention } \\
(\mathrm{N}=48)\end{array}$} & \multirow[t]{2}{*}{$\begin{array}{l}\text { Test of significance } \\
\text { (p) }\end{array}$} \\
\hline & No. & $\%$ & No. & $\%$ & \\
\hline \multicolumn{6}{|c|}{ Hand washing } \\
\hline Poor & 46 & 95.8 & 16 & 33.3 & \multirow[t]{3}{*}{$0.01 *$} \\
\hline Fair & 1 & 2.1 & 26 & 54.2 & \\
\hline Good & 1 & 2.1 & 6 & 12.5 & \\
\hline \multicolumn{5}{|c|}{ Alcohol based hand rub(ABHR) } & \multirow{4}{*}{$0.0001 *$} \\
\hline Poor & 2 & 4.2 & 0 & 0 & \\
\hline Fair & 15 & 31.3 & 0 & 0 & \\
\hline Good & 31 & 64.6 & 48 & 100 & \\
\hline \multicolumn{6}{|c|}{ Personal protective equipment (PPE) } \\
\hline Poor & 32 & 66.7 & 1 & 2.1 & \multirow{3}{*}{$.023 *$} \\
\hline Fair & 14 & 29.2 & 3 & 6.3 & \\
\hline Good & 2 & 4.2 & 44 & 91.7 & \\
\hline \multicolumn{6}{|c|}{ Sequence of wearing Gown } \\
\hline Poor & 8 & 16.7 & 3 & 6.3 & \multirow{3}{*}{$0.0001 *$} \\
\hline Fair & 6 & 12.5 & 2 & 4.2 & \\
\hline Good & 34 & 70.8 & 43 & 89.6 & \\
\hline \multicolumn{6}{|c|}{ Sequence of wearing Mask } \\
\hline Poor & 37 & 77.1 & 1 & 2.1 & \multirow{3}{*}{$.039 *$} \\
\hline Fair & 9 & 18.8 & 2 & 4.2 & \\
\hline Good & 2 & 4.2 & 45 & 93.8 & \\
\hline \multicolumn{6}{|c|}{ Sequence of wearing Goggles or Face Shield } \\
\hline Poor & 48 & 100 & 48 & 100 & \multirow{3}{*}{-} \\
\hline Fair & 0 & 0 & 0 & 0 & \\
\hline Good & 0 & 0 & 0 & 0 & \\
\hline \multicolumn{6}{|c|}{ Sequence of wearing gloves } \\
\hline Poor & 10 & 20.8 & 1 & 2.1 & \multirow{3}{*}{$.004 *$} \\
\hline Fair & 4 & 8.3 & 1 & 2.1 & \\
\hline Good & 34 & 70.8 & 46 & 95.8 & \\
\hline \multicolumn{6}{|c|}{ Sequence of removing gloves } \\
\hline Poor & 7 & 14.6 & 0 & 0 & \multirow{3}{*}{$.0001 *$} \\
\hline Fair & 26 & 54.2 & 5 & 10.4 & \\
\hline Good & 15 & 31.3 & 43 & 89.6 & \\
\hline
\end{tabular}

\# Test used was MCP: Monte Carlo Exact p value, *: statistically sig as p value $\leq .05$ 
Table.5 Effect of infection control training course on practice of studied medical interns. (continued)

\begin{tabular}{|c|c|c|c|c|c|}
\hline & \multicolumn{2}{|c|}{$\begin{array}{l}\text { Pre-intervention } \\
(\mathrm{N}=48)\end{array}$} & \multicolumn{2}{|c|}{$\begin{array}{c}\text { Post- intervention } \\
(\mathrm{N}=48)\end{array}$} & \multirow[t]{2}{*}{$\begin{array}{l}\text { Test of significance } \\
\text { (p) }\end{array}$} \\
\hline & No. & $\%$ & No. & $\%$ & \\
\hline \multicolumn{6}{|c|}{ Sequence of removing Goggles or Face Shield } \\
\hline Poor & 48 & 100 & 48 & 100 & \multirow[t]{3}{*}{-} \\
\hline Fair & 0 & 0 & 0 & 0 & \\
\hline Good & 0 & 0 & 0 & 0 & \\
\hline \multicolumn{5}{|c|}{ Sequence of removing gown } & \multirow{4}{*}{$0.0001^{*}$} \\
\hline Poor & 42 & 87.5 & 2 & 4.2 & \\
\hline Fair & 4 & 8.3 & 16 & 33.3 & \\
\hline Good & 2 & 4.2 & 30 & 62.5 & \\
\hline \multicolumn{6}{|c|}{ Sequence of removing mask } \\
\hline Poor & 40 & 83.3 & 0 & 0 & \multirow{3}{*}{$0.0001 *$} \\
\hline Fair & 6 & 12.5 & 5 & 10.4 & \\
\hline Good & 2 & 4.2 & 43 & 89.6 & \\
\hline \multicolumn{6}{|c|}{ Medication preparation } \\
\hline Poor & 3 & 6.3 & 0 & 0 & \multirow{3}{*}{$0.0001 *$} \\
\hline Fair & 45 & 93.8 & 19 & 39.6 & \\
\hline Good & 0 & 0 & 29 & 60.4 & \\
\hline \multicolumn{6}{|c|}{ Needle stick injury prevention } \\
\hline Poor & 45 & 93.8 & 2 & 4.2 & \multirow{3}{*}{$0.0001 *$} \\
\hline Fair & 3 & 6.3 & 29 & 60.4 & \\
\hline Good & 0 & 0 & 17 & 35.4 & \\
\hline \multicolumn{6}{|c|}{ Waste disposal } \\
\hline Poor & 47 & 97.9 & 0 & 0 & \multirow{3}{*}{$0.0001^{*}$} \\
\hline Fair & 1 & 2.1 & 0 & 0 & \\
\hline Good & 0 & 0 & 48 & 100 & \\
\hline \multicolumn{6}{|c|}{ Total score } \\
\hline Poor & 40 & 83.3 & 0 & 0 & \multirow{3}{*}{$0.0001 *$} \\
\hline Fair & 8 & 16.7 & 27 & 56.3 & \\
\hline Good & 0 & 0 & 21 & 43.8 & \\
\hline
\end{tabular}

\# Test used was MCP: Monte Carlo Exact p value, *: statistically sig as p value $\leq .05$

Previous studies have shown the impact of education and training on infection control measures and the incidence of nosocomial Infection. In Malaysia, the education of medical interns in the Pediatric Department at University Malaya Medical Centre resulted in a considerable reduction in the incidence of pediatric intensive care unit acquired bloodstream infections (Ng et al., 2015).

Statistically significant effects of the training course on the total score of knowledge of the studied participants were detected in this study. This was in line with Koo et al., (2016) who reported that educational interventions have improved the knowledge and practice 
pertaining to infection prevention among HCWs in the acute care. Previous literature suggested that the lack of infection control training programs is one of the major reasons for high rates of HCAI. Training courses have long been neglected due to limited resources, competing priorities, among other barriers (Borg, 2010; Tenna et al., 2013).

Moreover, practice and interventions are needed to increase the knowledge in the domains of sharp management and injuries and personal protective equipment among HCWs(Amin et al., 2013).On the other hand, it was reported that programs for infection control implemented in several hospitals were not enough to reduce the risk of exposure to infection among HCWs, suggesting that it is more a knowledge, behavior, and practice problem rather than facilities issue (El-Sayed et al., 2019).

In the current study, all participants were recently graduated with low clinical experience, which could have been reflected on the results of the study. This was in accordance with evidence suggesting that baseline knowledge and knowledge gain after educational intervention vary with job category and, perhaps, years of experience (Fitzpatrick et al., 2011; Mahramus et al., 2014). However, major advantages of this study included calculation of the sample size. There was improvement in Knowledge grades of studied participants after intervention. This study recommends integration of an infection control course among other clinical courses in the undergraduate medical students' curriculum, besides provision of continuous training on infection control measures to the recently-graduated either before the start of their internship or as an on-job training.

\section{Ethical approval}

This study was approved by Tanta Faculty of
Medicine Research Ethics Committee (REC). Consent to participate Formal written consent was taken from all study participants.

\section{References}

Alhraiwil, N. J., Amer, S. A., Dayel, M. E. B., AlYoussef, R. A., Alshlash, N. K., Alanazi, K. H., AlFozan, F. A., Asiri, A. S., AlSaihati, I. J., and Al-Shroby, W. A. (2020). Knowledge, Attitudes, and Practice of Hand Hygiene Guidelines among Health Care Providers: A National Perspective from Saudi Arabia: Practice of Hand Hygiene Guidelines among Health Care Providers. Journal of Health Informatics in Developing Countries. 14.

Amin, T. T., Al Noaim, K. I., Bu Saad, M. A., Al Malhm, T. A., Al Mulhim, A. A., and Al Awas, M. A. (2013). Standard precautions and infection control, medical students' knowledge and behavior at a Saudi university: the need for change. Global journal of health science. 5: 114-125.

Binalrimal, S., AlDrees, A., AlWehaibi, M., AlAsmary, M., AlShammery, A., AlHaidri, E., and AlQabbaa, L. (2019). Awareness and compliance of dental students and interns toward infection control at Riyadh Elm University. GMS hygiene and infection control. 14: Doc10-Doc10.

Borg, M. A. (2010). Prevention and control of healthcare associated infections within developing countries. International Journal of Infection Control. 6: 1-6.

El-Sayed, H., Mehanna, S., El Maraghy, N., Younes, S., Hassan, A., Sheded, M., and Khedr, Z. (2019). Assessment of doctors' knowledge, attitude and practice for hepatitis $\mathrm{C}$ virus infection control guidelines in Egypt. Archives of Medical Science-Civilization Diseases. 4: 34-40. 
Fitzpatrick, M., Everett-Thomas, R., Nevo, I., Shekhter, I., Rosen, L. F., Scheinman, S. R., Arheart, K. L., and Birnbach, D. J. (2011). A novel educational programme to improve knowledge regarding health care-associated infection and hand hygiene. Int $\mathbf{J}$ Nurs Pract. 17: 269-274.

Gupta, A., Anand, S., Sastry, J., Krisagar, A., Basavaraj, A., Bhat, S. M., Gupte, N., Bollinger, R. C., and Kakrani, A. L. (2008). High risk for occupational exposure to HIV and utilization of post-exposure prophylaxis in a teaching hospital in Pune, India. BMC Infectious Diseases. 8: 142.

Ho, S. S. K., Tse, M. M. Y., and Boost, M. V. (2012). Effect of an infection control programme on bacterial contamination of enteral feed in nursing homes. Journal of Hospital Infection. 82: 4955.

Huang, T. T., and Wu, S. C. (2008). Evaluation of a training programme on knowledge and compliance of nurse assistants' hand hygiene in nursing homes. Journal of Hospital Infection. 68: 164-170.

Ibrahim, A. A., and Elshafie, S. S. (2016). Knowledge, awareness, and attitude regarding infection prevention and control among medical students: a call for educational intervention. Advances in medical education and practice. 7 : 505-510.

Kermode, M., Jolley, D., Langkham, B., Thomas, M.S., and Crofts, N. (2005). Occupational exposure to blood and risk of bloodborne virus infection among health care workers in rural north Indian health care settings. American Journal of Infection Control. 33: 34-41.

Koo, E., McNamara, S., Lansing, B., Olmsted, R. N., Rye, R. A., Fitzgerald, T., and Mody, L. (2016). Making infection prevention education interactive can enhance knowledge and improve outcomes: Results from the Targeted Infection Prevention (TIP) Study. American Journal of Infection Control. 44: 1241-1246.

Lobo, D., Sams, L. M., and Fernandez, S. L. (2019). Correlation between health professionals' knowledge, attitude and practice about infection control measures. Journal of Medical \& Allied Sciences. 9: 26-31.

Mahramus, T., Penoyer, D. A., Frewin, S., Chamberlain, L., Wilson, D., and Sole, M.L. (2014). Assessment of an educational intervention on nurses' knowledge and retention of heart failure self-care principles and the Teach Back method. Heart \& Lung. 43: 204-212.

Mathis, S., Ehlman, K., Dugger, B. R., Harrawood, A., and Kraft, C. M. (2013). Bladder buzz: the effect of a 6week evidence-based staff education program on knowledge and attitudes regarding urinary incontinence in a nursing home. J Contin Educ Nurs. 44: 498-506.

Ng, Y. Y., Abdel-Latif, M. E.-A., Gan, C. S., Siham, A., Zainol, H. \& Lum, L. C. S. (2015). Impact of infection control training for interns on PICU-acquired bloodstream infections in a middleincome country. Singapore medical journal, 56: 506-512.

Park, S., Jeong, I., Huh, J., Yoon, Y., Lee, S., and Choi, C. (2008). Needle stick and sharps injuries in a tertiary hospital in the Republic of Korea. American Journal of Infection Control. 36: 439443.

Tartari, E., Fankhauser, C., Masson-Roy, S., Márquez-Villarreal, H., Fernández Moreno, I., Rodriguez Navas, M. L., Sarabia, O., Bellissimo-Rodrigues, F., Hernández-de Mezerville, M., Lee, Y. 
F., Aelami, M. H., Mehtar, S., Agostinho, A., Camilleri, L., Allegranzi, B., Pires, D., and Pittet, D. (2019). Train-the-Trainers in hand hygiene: a standardized approach to guide education in infection prevention and control. Antimicrobial Resistance \& Infection Control. 8: 206.

Tenna, A., Stenehjem, E. A., Margoles, L., Kacha, E., Blumberg, H. M., and Kempker, R. R. (2013). Infection control knowledge, attitudes, and practices among healthcare workers in Addis Ababa, Ethiopia. Infection control and hospital epidemiology. 34: 1289-1296.

Wada, K., Narai, R., Sakata, Y., Yoshikawa, T., Tsunoda, M., Tanaka, K., and Aizawa, Y. (2007). Occupational exposure to blood or body fluids as a result of needle stick injuries and other sharp device injuries among medical residents in Japan. Infect Control Hosp Epidemiol. 28: 507-509.

Wang, J., Liu, F., Tan, J. B. X., Harbarth, S., Pittet, D., and Zingg, W. (2019). Implementation of infection prevention and control in acute care hospitals in Mainland China - a systematic review. Antimicrobial Resistance \& Infection Control. 8: 32.

Xiong, P., Zhang, J., Wang, X., Wu, T. L., and Hall, B. J. (2017). Effects of a mixed media education intervention program on increasing knowledge, attitude, and compliance with standard precautions among nursing students: A randomized controlled trial. American Journal of Infection Control. 45: 389-395.

\section{How to cite this article:}

Aya Farag El Sebaey, Samir Abd El MageedAtlam, El Sayed Abd El Rahman El Kafas and Hanaa Abd El Aziz Zayed. 2021. Infection Control Knowledge of Medical Interns before and after Training Intervention in Tanta University Hospital in Egypt. Int.J.Curr.Microbiol.App.Sci. 10(06): 440-450. doi: https://doi.org/10.20546/ijcmas.2021.1006.047 